\title{
STRAIN MARKINGS IN MILD STEEL UNDER TENSION
}

\author{
By Henry S. Rawdon
}

\begin{abstract}
Polished tension bars were examined during the tension test to determine the stress and corresponding elongation at which strain markings appear. The mode of propagation of the strain effect throughout the bar has been determined by repeated loadings on the same bar. Hardness increases about 5 per cent during the formation of strain markings, this increase being about one-tenth of that occurring when the same steel is stressed to fracture. Strain markings result from deformation by slip within a relatively few suitably oriented ferrite grains. This slip is accompanied by a general shifting and tilting of neighboring grains, however, which results in the characteristic rippled surface appearance of strain markings on steel. Similar markings were observed on an aluminum alloy.
\end{abstract}

\section{CONTENTS}

I. Introduction

II. Materials and method

III. Results:

1. Tension tests of polished specimens

2. Effect of repeated loading

3. Hardness of strained areas

4. X-ray examination _._. 476

5. Microstructure

6. Comparison with an aluminum alloy

IV. Discussion

V. Summary

\section{INTRODUCTION}

I he mode of deformation of metals under stress has long been a subject of interest. The observation of Lüders, whose name is generally associated with the macroscopic markings on metals which have been strained, dating from about 1854, was one of the earliest published on this subject. ${ }^{1}$ The same phenomena had been observed, however, as early as 1836 by Piobert. ${ }^{2}$ The name of Hartmann, who, at a much later date ${ }^{3}$ studied this phenomenon at great length, is

1 W. Lüders, Ueber die Aeusserung der Elasticität an Stahlartigen Eisenstaben und Stahlstaben, und über eine beim Biegen solcher Stabe beobachtete Molecularbewegung, Dingler's Pol. J., 155, p. 18; 1860.

${ }_{2}^{2}$ Memorial de l'Artillerie, $\mathbf{V}$, p. 505; 1842; see, also, C. Fremont, La cause de la formation du palier dans l'essai de traction des aciers doux, La Génie Civil, 82, p. 176; 1923.

${ }^{3}$ L. Hartmann, Sur la distribution des déformations dans les métaux soumis à des efforts, Comptes Rendus, 118, p. 520; 1894; Distribution des déformations dans les métaux soumis à des efforts (booklet); 1896, Berger-Levrault et Cie., Paris and Nancy; Phênomènes qui accompagnent la déformation permanente des métaux, Congrès International des Méthodes d'essai, 1, p. 95; 1901; Sur le mécanisme de la déformation permanente dạns les métaux soumis à l'extension, Comptes Rendus, 152, pp. 1005, 1084, 1233; 1911. 
often linked with that of Lüders in referring to the markings on steel specimens which have been permanently strained.

Numerous other descriptions of this phenomenon have appeared in the technical literature. Of these, the articles by Gulliver ${ }^{4}$ and Mason ${ }^{5}$ are especially noteworthy, since these investigators have done much in correlating the formation of the strain lines with the magnitude and nature of the stress applied to the specimen.

Aside from the extensive studies which have been made on the microscopic aspects of the deformation of metals, the most recent work dealings with the general subject of strain in metals relates primarily to methods for revealing the strained portions. The special etching method described by Fry ${ }^{6}$ for revealing strain lines and areas in the macrostructure of steel and applied later by Turner and Jevons ${ }^{7}$ and by Fell ${ }^{8}$ in their very comprehensive studies has proved a noteworthy contribution to our knowledge on this subject.

An excellent series of descriptive articles on the general subject of strain lines is that of Seigel. ${ }^{9}$ The most recent article on this subject, which deals particularly with the theoretical aspects of the underlying cause, is that of Takaba and Okuda. ${ }^{10}$

Despite the numerous articles which have been published on the subject of strain lines there are a number of very important points which are still obscure. Although it is generally assumed that the formation of these lines is a special case of the deformation of a metal by slip, very little has been accomplished to make clear the microstructural changes which underlie this phenomenon. In addition to the stress at which the strain lines first appear, it is also of importance to know the behavior of the material, as revealed by the change in the number and extent of the strain lines; that is, their "propagation" throughout the stressed specimen, as the specimen is maintained under constant load. Considerable information on this "propagation of strain" has been given by the work of Turner and Jevons ${ }^{11}$ who applied the etching method of Fry to a series of tension bars which had been permanently strained, each by a different amount. A series of observations taken on the same bar while under stress, however, would be preferable in many respects to the use of a number

4 G. H. Gulliver, "Some phenomena of permanent deformation in metals," Proc. Inst. Mech. Engrs., pts. 1 and 2, p. $141 ; 1905$.

5 W. Mason, “The Lüder's lines on mild steel,” Proc. Phys. Soc. of London, 23, p. 305; 1911.

${ }^{6}$ Adolf Fry, “Kraftwirkungsfiguren in Flusseisen dargestellt durch ein neues Ätzverfahren,” Kruppsche Monatshefte, 2, p. 117, 1921; Stahl und Eisen, 41, p. 1093; 1921.

7 T. H. Turner and J. D. Jevons, "The detection of strain in mild steel," J. Iron Steel Inst., 111, p. 169; 1925. J. D. Jevons, "Strain detection in mild steel by special etching," J. Iron Steel Inst., 111, p. 191; 1925.

${ }^{8}$ Eric W. Fell, "Strain in steel (experiments upon the nature and detection of certain phenomena observed in permanently deformed steel)," J. Iron Steel Inst., Carnegie Schol. Mem., 16, p. 101; 1927.

• J. Seigel, "Les premièrs déformations permanentes dans les aciers doux," Le Génie Civil, 88, pp. 315, 332, 357; 1926; also "Condition d'apparition des lignes de cession," Le Génie Civil, 90, 576; 1927.

10 Ititaro Takaba and Katumi Okuda, "Die wichtigsten Eigenschaften und die Theorie der Fliessfiguren,” Archiv für das Eisenhüttenwesen, 1, No. 7, p. 511; January, 1928.

11 See footnote 7, p. 468. 
of different bars of the same nominal composition. The present study has been carried out in the endeavor to obtain more definite information on these points. The work has been restricted almost entirely to low-carbon steel bars stressed in tension; a few supplementary observations, however, were made on an aluminum alloy by way of comparison.

\section{MATERIALS AND METHOD}

Low-carbon steel of boiler-plate grade was used for most of the specimens. The average composition of this steel, which was used in the hot-rolled condition, was: C, 0.17 per cent; $\mathrm{Mn}, 40 ; \mathrm{P}, 0.02$; S. 0.033. For the X-ray study, as well as for some of the microscopic examinations, steel strip, 0.0025 inch thick, made by the continuous rolling process was used. This strip steel contained 0.23 per cent carbon and 0.35 per cent manganese, and prior to use the material was annealed two hours at $750^{\circ}$ C., a number of strips of the thin material being clamped between two steel plates in order to reduce oxidation and to keep the strips flat.

Tension specimens, 18 inches in length and 2 inches wide, with a reduced section $1 \frac{1}{2}$ inches wide, the parallel portion of which was 9 inches long, were cut from the $3 / 8$-inch boiler plate. On one side of the bar the oxide scale was allowed to remain intact while the other side was machined free from scale. The reduced section of the bar was polished before testing. A few specimens of boiler-plate steel, with dimensions one-half those given, were also used. All of the specimens cut from the thin strip steel were of the smaller size.

The specimens were stressed in an Amsler testing machine, three types of grips for holding the specimens being used in different tests. All of the 18-inch bars were tested by means of the usual type of wedge grips. For most of the smaller specimens grips designed to give a very close approach to true axial tension ${ }^{12}$ were used. A special form of grip, ${ }^{13}$ which has been used with pronounced success at the Bureau of Standards for the tension testing of small members which have been formed out of thin sheet metal, such as the duralumin lattice bars of airship girders, such members being tested in their finished shape - that is, without any preliminary flattening before testing-were also used. The appearance of the strain lines obtained was not essentially different for the three forms of grips; that is, so far as the general character and orientation of the first lines which formed are concerned. The results given below may be considered as representative of results obtained with all of the grips used.

Measurements of the elongation under load were made on a number of the 18-inch bars, a Ewing extensometer being used.

\footnotetext{
12 Tentative methods of tension testing of metallic materials, E8-25T, Proc. Am. Soc. Test. Matls., 25, p. $858 ; 1925$.

${ }^{13}$ Developed at the Bureau of Standards by Dr. L. B. Tuckerman, engineer physicist. A description of this device has not been published as yet.
} 


\section{RESULTS}

\section{TENSION TESTS OF POLISHED SPECIMENS}

Observations made on the polished surface of a bar as the load was applied, as compared with observations on the other side of the bar from which the oxide (mill scale) had not been removed, showed very plainly that accurate results can be obtained only with a polished specimen. Not only were the sharp lines and fine details of the pattern entirely lacking on the scaled surface, but an appreciably longer time, when the load was maintained constant, was required in order to cause flaking of the oxide and thus reveal the strain markings. When the load was maintained as close as practicable to that which caused strain lines to appear on the polished surface, approximately 30 minutes elapsed before any evidence whatever of flaking of the oxide scale was observed. When the load on a specimen was maintained for a rather long time at a value just above that which was sufficient to cause the formation of strain lines, the effect gradually progressed from the fillet end of the reduced section of the bar toward the center of the specimen. In most cases the effects at the two ends of the bar were essentially the same. As seen on the scaled side of the specimen, the boundary surface between the strained and the unstrained portion as it progressed along the stressed bar "lagged" noticeably behind that as seen on the polished side. On the large tension specimens (18-inch) this "lag" was approximately $1 / 2$ inch. Observations on strain markings on mild-steel specimens stressed in tension as revealed by the flaking of a coating of mill scale on such material indicate that this method and possibly also methods depending upon the use of other coatings, such as "whitewash,"14 are most useful in a qualitative sense for locating the strained areas rather than for an accurate indication of the stress necessary for the formation of such strain markings.

When a specimen is stressed in tension, the strain lines first appear in the reduced section just below the fillet. As can be shown by optical methods, ${ }^{15}$ in this portion of the stressed bar the stress is considerably greater than elsewhere throughout the reduced section. The lines originate at the edge and progress across the width of the bar. In the specimens used the lines at the two ends originated at opposite sides of the bar. The course of the first one at each end was approximately perpendicular to the axis of the bar instead of following an angle of 45 or $50^{\circ}$ as is usually considered typical for such markings. Presumably this was on account of the stress on specimen not being perfectly axial. This effect was noted, however,

\footnotetext{
${ }_{14}$ Bureau of Standards Miscellaneous Publications No. 72; also R. S. Johnston, Compressive Strength of Column Web Plates and Wide Web Columns, Tech. Paper No. 327, 1926.

15 E. G. Coker, "Photo-elastic methods of testing." Report of British Asso. Advancement of Science, 92, p. 313, 1924; also, "Elasticity and plasticity," Thirteenth Thomas Hawkley Lecture, Proc. Inst. Mech. Eng., pt. 2, p. 897, 1926.
} 
B. S. Journal of Research, RP15

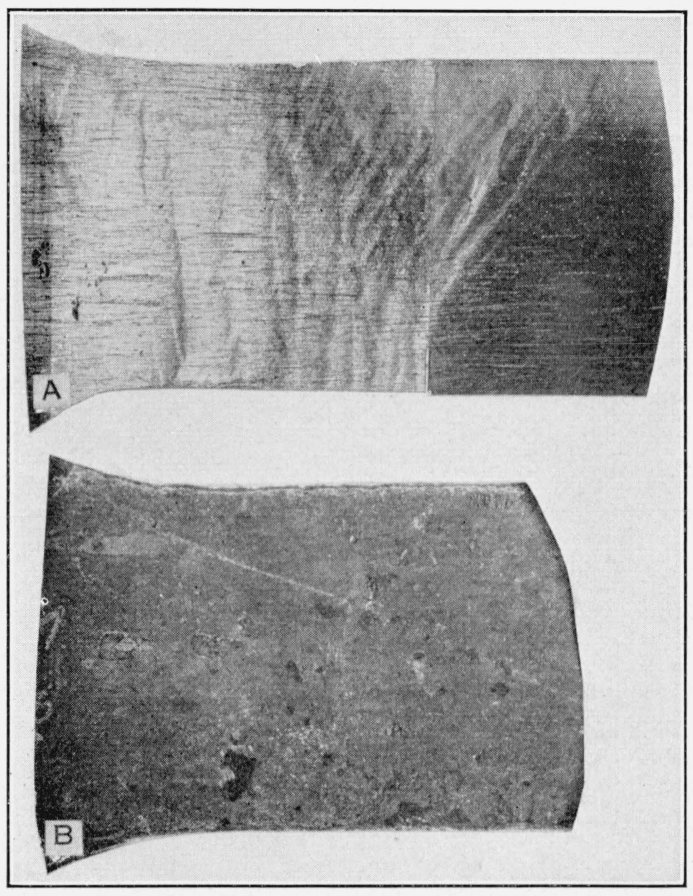

FIG. 1.-Strain markings on soft steel as seen on a polished surface and on one covered with mill scale. $\times 1$

Specimen 3 (Table 1), the first line appeared near the fillet at $32,000 \mathrm{lbs} . / \mathrm{in} .{ }^{2}$, stress was raised to $33,800 \mathrm{lbs} . / \mathrm{in}^{2}{ }^{2}$ and held five minutes; $a$, the surface was polished before stressing; $b$, opposite surface on which the mill scale was left intact 


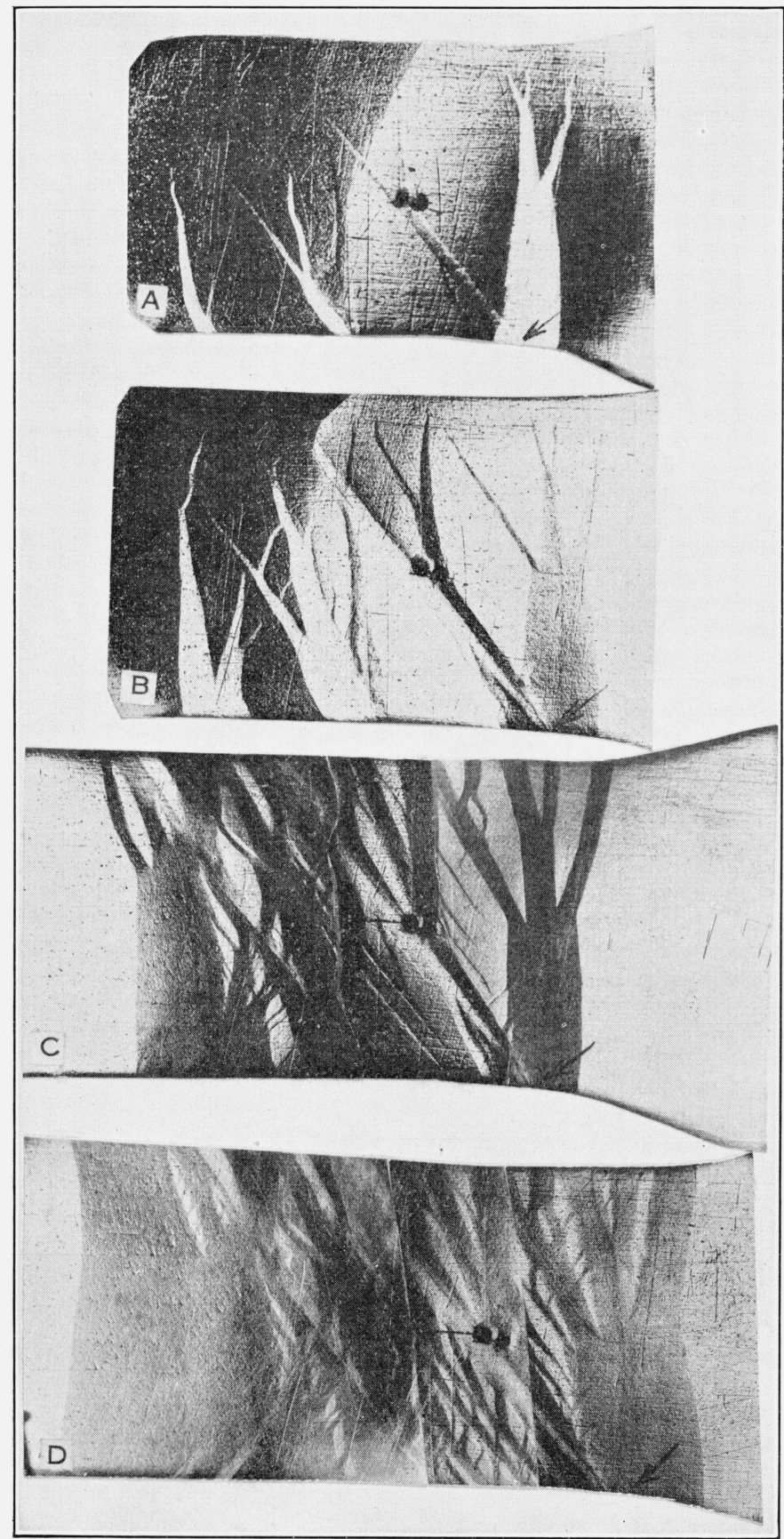

FIG. 3.-Strain markings which formed at one end of specimen 7 when subjected to the first four loadings of Figure $2 . \times 1$

The specimens were photographed under "vertical" illumination; $a, b, c$, and $d$, loadings $1,2,3$, and 4 . Note that the extensometer readings given in Figure 2 correspond to only those strain markings within the gauge marks, in both Figures 3 and 4 . The arrows indicate the base of the fillet 
on all specimens, regardless of the type of grips used for holding them. In the specimens which were stressed until fracture occurred the location of the fracture appeared to bear no obvious relation to the preexisting strain lines or the point where the "deformation waves" progressing from the two ends met, except in one case. The first strain lines to appear in this specimen (No. 11, Table 1) formed at a considerable distance from the fillet, and the fracture, when the specimen was broken, occurred close to this point.

TABLE 1.-Summary of specimens of boiler-plate steel tested

\begin{tabular}{|c|c|c|c|c|c|}
\hline $\begin{array}{l}\text { Specimen No. } \\
\text { and size }\end{array}$ & $\begin{array}{l}\text { Stress } \\
\text { at } \\
\text { which } \\
\text { strain } \\
\text { lines } \\
\text { ap- } \\
\text { peared }\end{array}$ & $\begin{array}{l}\text { Length of } \\
\text { time load } \\
\text { was held }\end{array}$ & $\begin{array}{l}\text { Observations on } \\
\text { oxide scale }\end{array}$ & $\begin{array}{l}\text { Disposition made of } \\
\text { specimen }\end{array}$ & Remarks \\
\hline 1 (18-inch) - & $\begin{array}{l}\text { Lbs./in. }{ }^{2} \\
33,800\end{array}$ & 60 minutes. & & & $\begin{array}{l}\text { Strain lines formed just } \\
\text { below fillet and pro- } \\
\text { gressed toward cen- } \\
\text { ter; bar was loaded } \\
\text { to failure; loeation of } \\
\text { the fracture bore no } \\
\text { obvious relation to } \\
\text { the strain lines. }\end{array}$ \\
\hline 2 (18-inch) & $\begin{array}{r}130,200 \\
33,800\end{array}$ & 5 hours. & $\begin{array}{l}\text { First lines on } \\
\text { oxide seen } 25 \\
\text { minutes after } \\
\text { those on pol- } \\
\text { ished surface. }\end{array}$ & $\begin{array}{l}\text { Tension test, ult. ten. } \\
\text { str. } 56,700 \mathrm{lb} . / \text { in. }^{2} ; \\
\text { e long a t i o n (8 } \\
\text { inches), } 33 \text { per cent. }\end{array}$ & \\
\hline 3 (18-inch) & 32,000 & $\begin{array}{l}5 \text { minutes at } \\
33,800 \mathrm{lbs} . / \\
\text { in. }^{2}\end{array}$ & & $\begin{array}{l}\text { Hardness survey after } \\
\text { first loading and af- } \\
\text { ter breaking, uit. ten. } \\
\text { str. 55,600 lbs./in. }{ }^{2} \\
\text { elongation ( } 8 \text { inches) } \\
33 \text { per cent. }\end{array}$ & \\
\hline 4 (18-inch) & 33,400 & & & & $\begin{array}{l}\text { Increase in Brinell } \\
\text { hardness in strain } \\
\text { markings, } 3 \text { per cent; } \\
\text { increase in Rockwell } \\
\text { in strain markings, } \\
4.3 \text { per cent; increase } \\
\text { in B. H. N. after ten- } \\
\text { sion test, } 44 \text { per cent; } \\
\text { increase in Rockwell } \\
\text { after tension test, } 43 \\
\text { per cent. }\end{array}$ \\
\hline 5 (18-inch) & $\begin{array}{r}128,600 \\
30,200 \\
32,000\end{array}$ & 30 minutes . - & $\begin{array}{l}\text { No flaking of } \\
\text { oxide scale. }\end{array}$ & $\begin{array}{l}\text { Examination of micro- } \\
\text { structure. }\end{array}$ & \\
\hline $6(9$-inch) -- & $\begin{array}{r}132,800 \\
33,600 \\
34,300\end{array}$ & & & & \\
\hline 7 (18-inch) & $\begin{array}{r}28,700 \\
29,700 \\
28,800 \\
31,300 \\
30,600\end{array}$ & & & $\begin{array}{l}\text { Tension test, ult. ten. } \\
\text { str. } 54,000 \text { lbs./in. } \\
\text { e lo n g a t i o n } \\
\text { inches), } 33.5 \text { per } \\
\text { cent. }\end{array}$ & See Figure 2. \\
\hline 8 (9-inch) & 33,500 & 40 minutes. & & Used for hardness tests. & 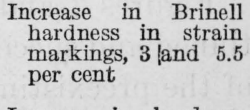 \\
\hline 10 (18-ine & $\begin{array}{r}27,500 \\
31,000\end{array}$ & 10 minutes & & Used for hardness tests. & $\begin{array}{l}\text { Increase in hardness } \\
\text { in strain markings, } \\
\text { Brinell hardness, } 4.5 \\
\text { and 5.5 per cent; } \\
\text { Rockwell, 8 per cent. } \\
\text { (See fig 7.) }\end{array}$ \\
\hline 11 (18-inch) & 28,200 & & & $\begin{array}{l}\text { Tension test and hard- } \\
\text { ness, ult. ten. str. } \\
56,900 \text { lbs./in. }{ }^{2} ; \text { elon- } \\
\text { gation (8 inches), } \\
31 \text { per cent. }\end{array}$ & $\begin{array}{l}\text { Increase in hardness, } \\
\text { Brinell hardness, } 47 \\
\text { per cent; Rockwell, } \\
47 \text { per cent. (See } \\
\text { fig. 7.) }\end{array}$ \\
\hline
\end{tabular}

1 The stresses given mark the first appearance and suecessive distinct stages in the development of the strain lines.

${ }_{2}^{2}$ The specimen was loaded successively several times, each stress indicating the appearance of new lines for each particular loading. 
In Table 1 is given a summary of the results obtained with the specimens of the boiler-plate steel used in the study of strain markings.

\section{EFFECT OF REPEATED LOADING}

The general character of strain lines and their mode of "propagation" along the length of the bar as it is stressed in tension are best shown by the results obtained with specimen No. 7 (figs. 2 to 6 , inclusive), which was loaded five times in succession, the specimen being removed from the machine after each loading for observation and photographing. In order to secure good contrast between the strained areas and the unstrained portions, in the photographing of the specimens, which was done under "vertical" illumination, only a rather small part of the bar could be photographed at a time. The smaller views were then assembled in proper order so as to give the complete picture of the specimen. The diagrams of Figure 6, showing the "growth" in the strained areas with prolonged loading, were obtained by tracing directly on tracing linen the image of the stressed bar, after removal from the machine, as projected on to the ground glass of the metallurgical camera.

The behavior of the specimen when loaded several times and the load released between successive loadings is summarized graphically in Figure 2. The elongation of the specimen was measured on an 8-inch gauge length by means of a Ewing extensometer (18-inch tension bar). Other details, such as the length of time the load was maintained constant, together with the extension produced, the length of time which elapsed between loadings, the stress at which strain markings first appeared during each loading, as well as the different "permanent sets" produced have also been given. It will be noted that in each case the first appearance of strain markings either coincided with the "break" in the stress-strain curve or occurred immediately after the break. When a specimen has been sufficiently strained in a previous loading, so as to produce strain markings, it is exceedingly difficult to detect first indication of the formation of additional strain lines during a subsequent loading.

Figures 3 and 4 clearly show that the strain lines under long continued and successive loadings "grow" by the widening and branching of the preexisting lines as well as by the formation of new lines. In a number of cases (fig. 6, fourth and fifth loading) the "front" of the strained area which extended completely across the specimen was seen to progress uniformly along the length of the bar, from each end, no new or additional strain lines being formed. It is of interest to note that at the end of the fifth loading, when the load was released, these two "fronts" which had not yet met differed appreciably in the angle which they formed with the axis of the specimen; that is, 
B. S. Journal of Research, RP15

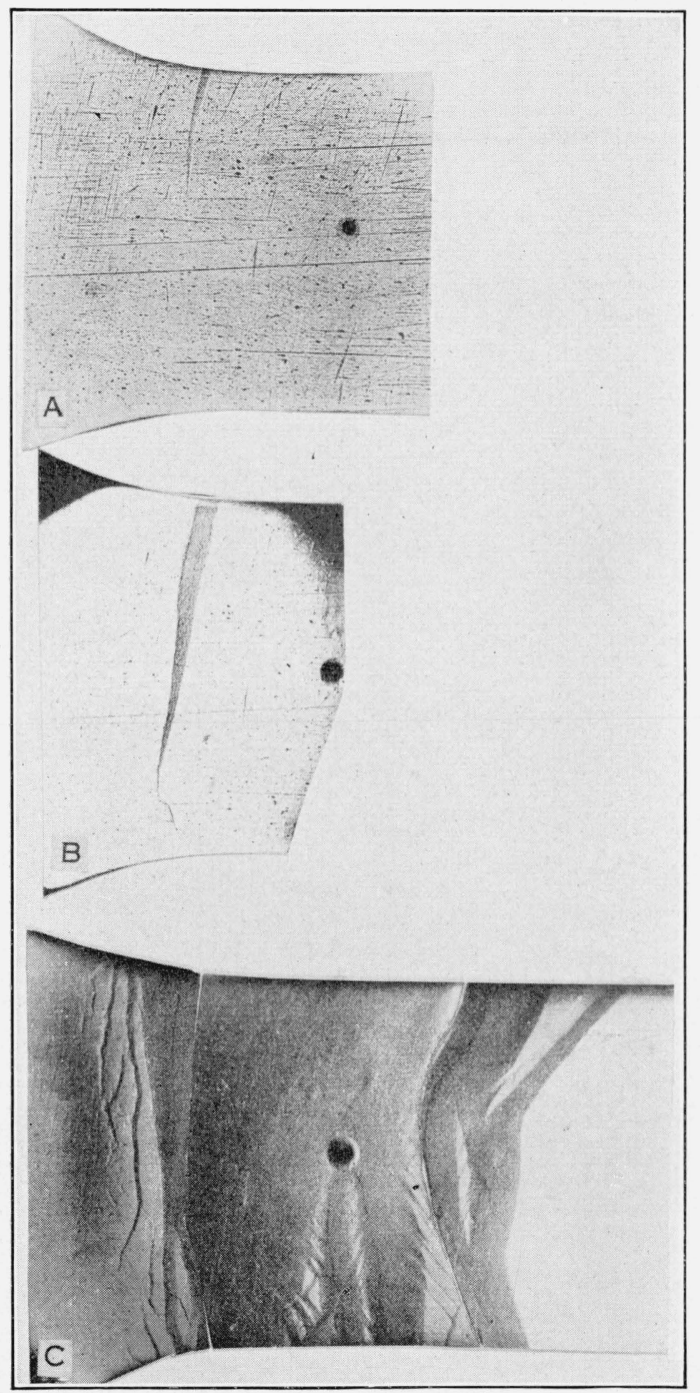

FIG. 4.-Strain markings which formed at the opposite end of specimen 7, to that shown in Figure 3, when stressed as in Figure $2 . \times 1$

$a, b$, and $c$, loadings 1,3 , and 4 
B. S. Journal of Research, RP15

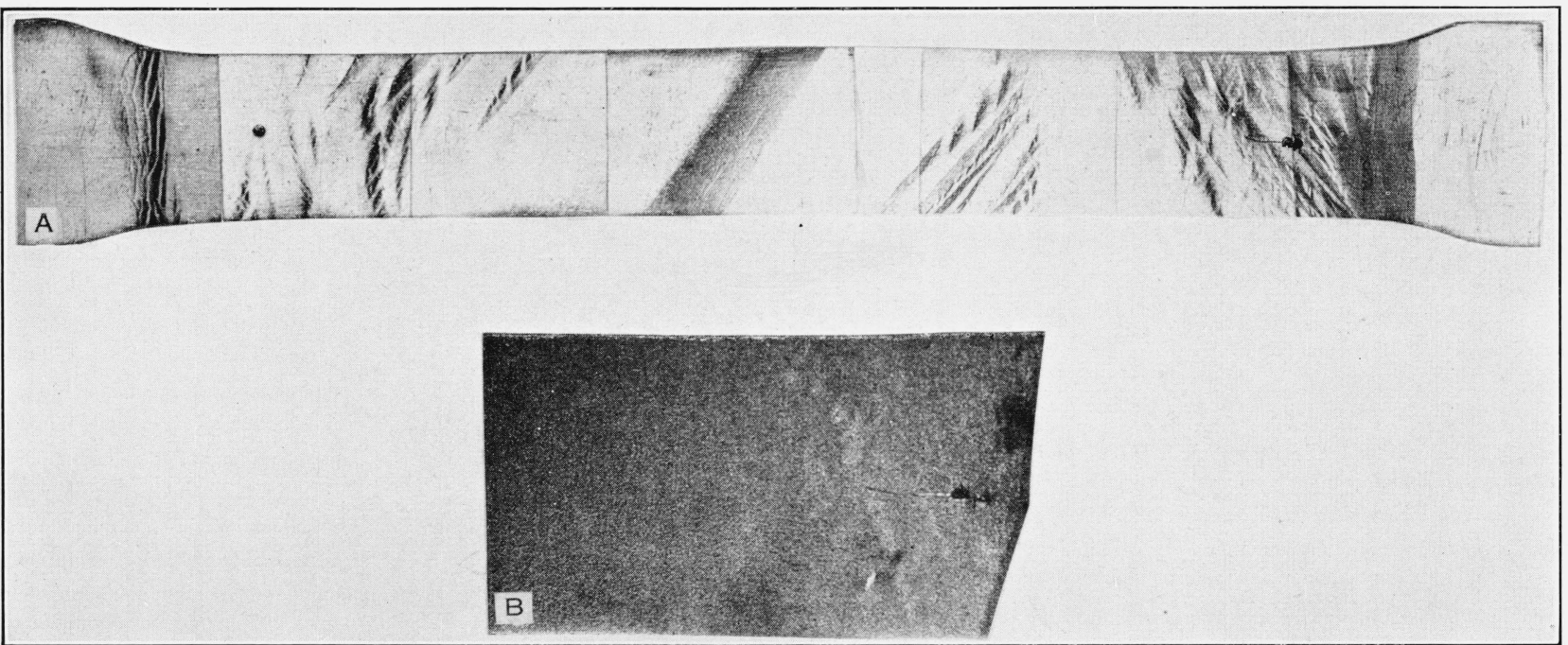

Fig. 5.-Strain markings on specimen 7 (Table 1) after being loaded sufficiently to strain approximately the entire reduced section and also after being broken in tension

$a$, appearance of the bar after loading 5, Figure 2. Note the diagonal section still free from strain markings, slightly less than $\times 1 / 2 ; b$, one end (upper end of $a$ ) of specimen 7 after being broken in tension. $\times 1$. Only traces of the most conspicuous preexisting strain markings persist 
the fronts of the two deformation "waves" advancing from the ends of the specimen were not parallel. It will be seen from Figure 6 that although the two deformation "waves" had traveled nearly the length of the reduced section islands of apparently unstrained metal still remained at a considerable distance behind the "front."

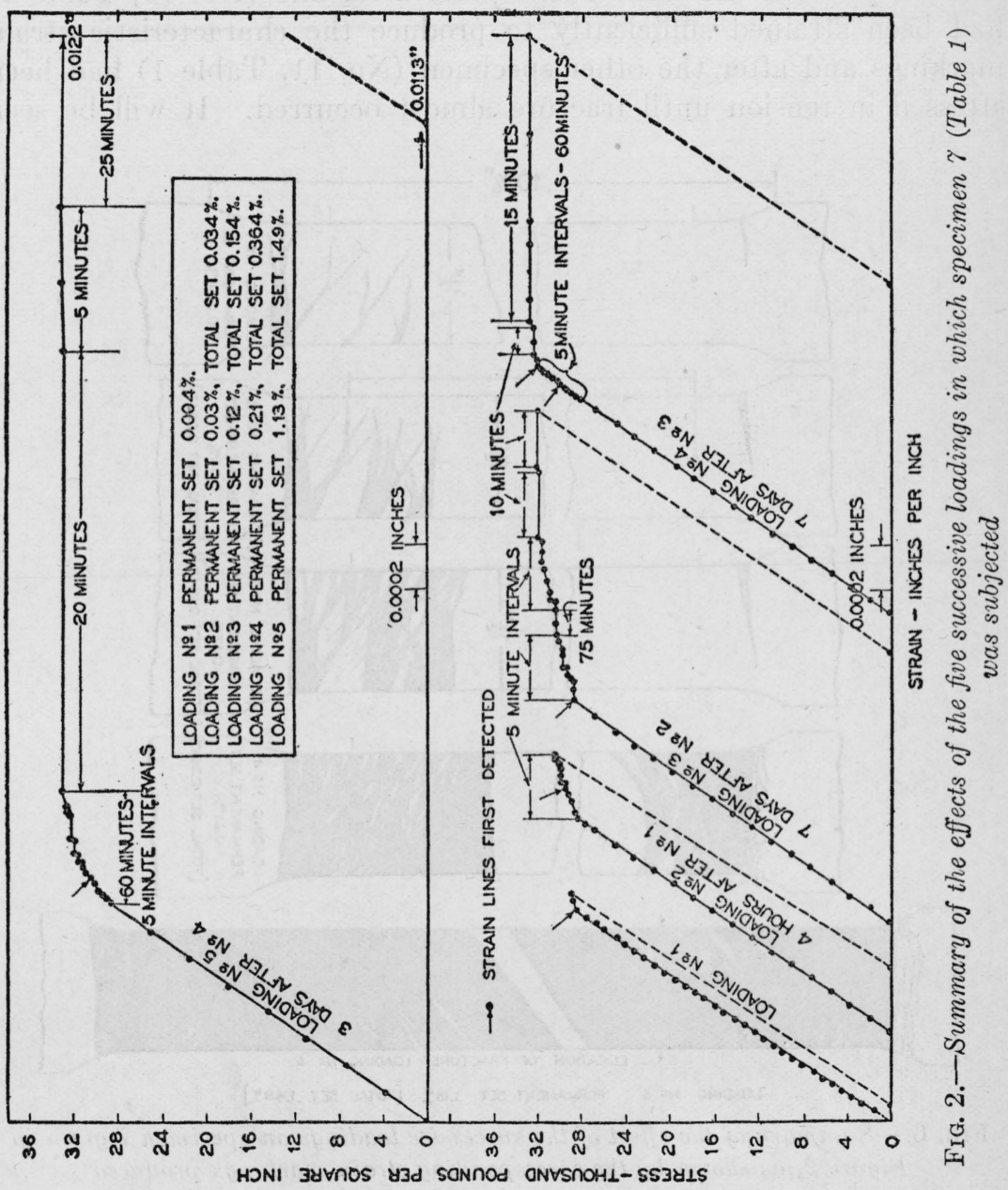

The results summarized in Figure 2 give no indication of strengthening of the material by overstraining. Since, as shown in Figure 6, the effect of each successive loading is confined to that portion of the reduced section which was not affected by the previous loading, the phenomenon of strengthening by overstraining would not be expected to occur until the entire reduced section had been affected; that is, had shown the "initial straining" effect. 


\section{HARDNESS OF STRAINED AREAS}

It is well known that the effect of permanently straining mild steel is to increase its hardness. In Figure 7 are summarized the results of hardness tests by the Brinell and the Rockwell methods made on two of the 18-inch tension bars which were cut from adjacent strips from the same boiler plate after one (No. 10, Table 1) had been strained sufficiently to produce the characteristic strain markings and after the other specimen (No. 11, Table 1) had been stressed in tension until fracture almost occurred. It will be seen
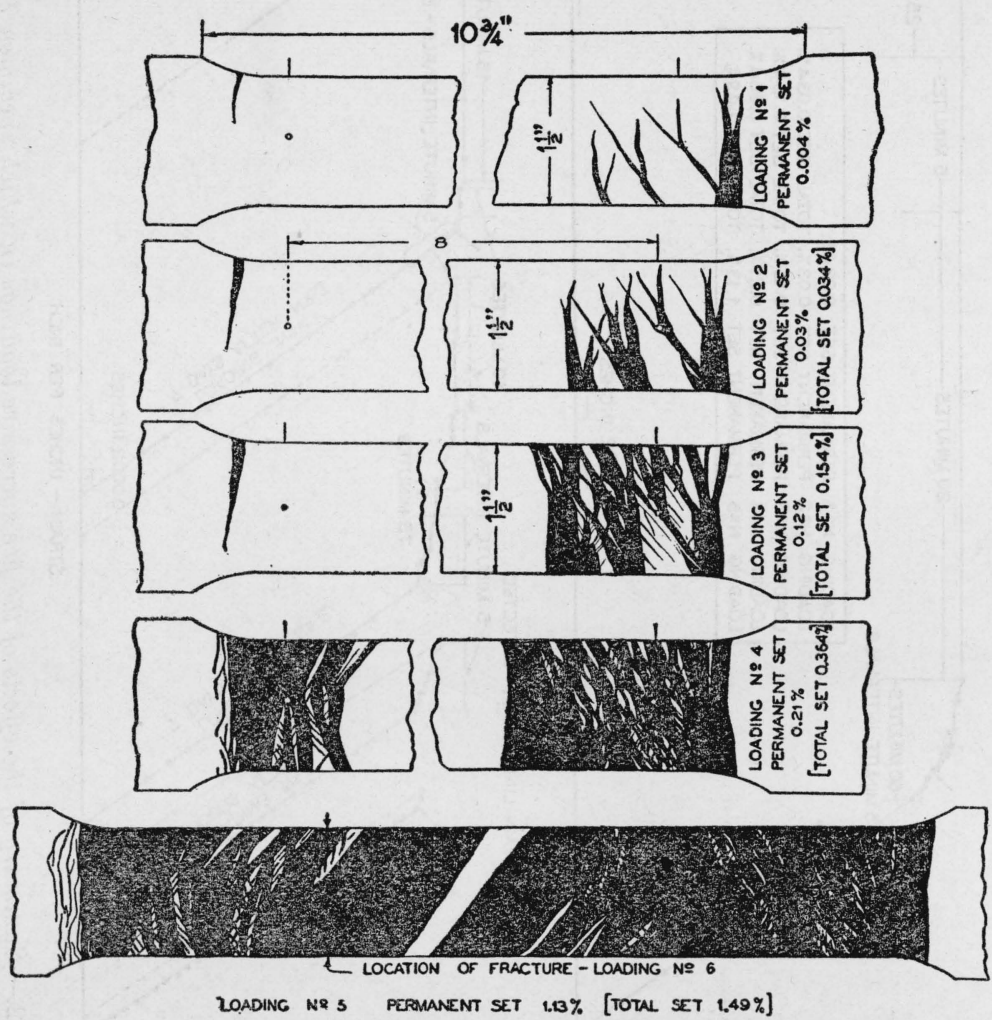

FIG. 6.-Summary of the effect of the successive loadings on specimen 7 given in

Figure 2, as shown by the corresponding strain markings produced

that the hardness of the strained areas is somewhat greater than that of the adjacent "unstrained" metal which had the same hardness as the metal before the application of any load whatever.

The increase in hardness in the strain markings over that of the unstrained metal was slight, it varied in different specimens from 3 to 8 per cent according to the method used for measuring hardness. According to the Rockwell method an increase of hardness of 4.3 per cent was produced on one specimen (No. 3, Table 1). On the 
same bar the Brinell method (10 mm ball, 3,000 $\mathrm{kg}$ load) indicated an increase in hardness of 3 per cent. On another bar (specimen 9) the effect of straining sufficiently to produce the strain figures caused an increase in hardness in the strain areas at the two ends of the bar of 3 and 5.5 per cent, respectively, as determined by the Brinell method in which a $1 \mathrm{~mm}$ ball and a load of $25.6 \mathrm{~kg}$ was used. The increase in hardness in the strain markings shown in Figure 7 over

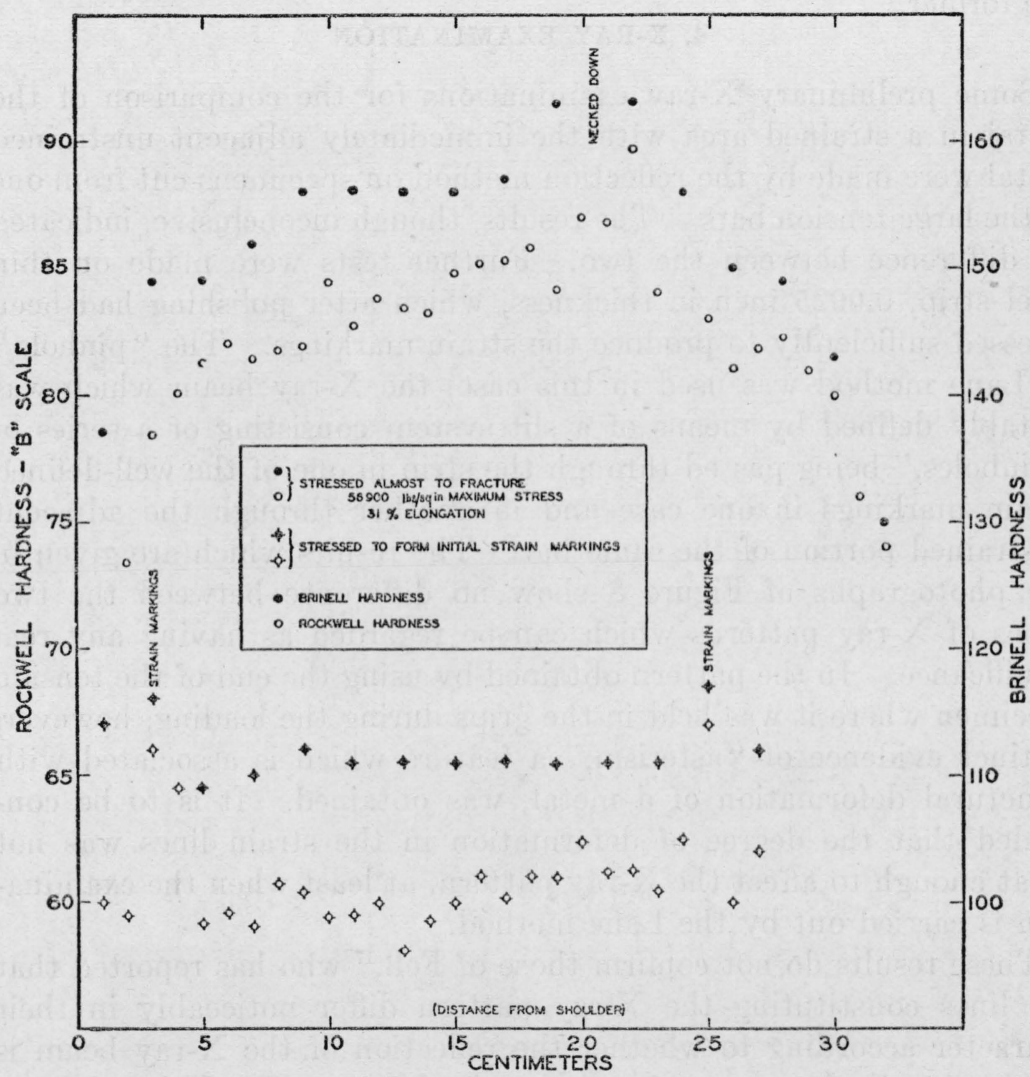

Fra. 7.-Hardness survey of tension bars of soft steel (a) stressed sufficiently to form strain markings and (b) pulled until "necking down" almost to fracture occurred, specimens 10 and 11, respectively, Table 1

the hardness of the unstrained metal was 5 per cent by the Brinell method and 8 per cent by the Rockwell.

These values are in fair agreement with the increase in hardness reported by Fell, ${ }^{16}$ who found an increase of 6.8 per cent in the strain figures of soft steel produced by breaking a notched bar in tension. Fell's measurements, however, were made upon steel which had been tempered somewhat subsequently to straining, and this

16 See footnote 8, p. 468.

$.110598^{\circ}-28-2$ 
fact may account for some of the difference between his results and those reported here.

The increase in hardness produced by the preliminary loading which resulted in the formation of the strain figures was small as compared with that produced by stretching the bar until fracture was produced. As shown in Figure 7 and Table 1, the maximum increase in hardness in the latter case was about ten times that of the former.

\section{X-RAY EXAMINATION}

Some preliminary X-ray examinations for the comparison of the metal in a strained area with the immediately adjacent unstrained metal were made by the reflection method on specimens cut from one of the large tension bars. The results, though inconclusive, indicated no difference between the two. Further tests were made on thin steel "strip, 0.0025 inch in thickness, which after polishing had been stressed sufficiently to produce the strain markings. The "pinhole" or Laue method was used in this case, the X-ray beam which was suitably defined by means of a slit system consisting of a series of "pinholes," being passed through the strip in one of the well-defined strain markings in one case and in another through the adjacent unstrained portion of the same bar. The results which are given in the photographs of Figure 8 show no difference between the two types of X-ray patterns which can be regarded as having any real significance. In the pattern obtained by using the end of the tension specimen where it was held in the grips during the loading, however, distinct evidence of "asterism," a feature which is associated with structural deformation of a metal, was obtained. It is to be concluded that the degree of deformation in the strain lines was not great enough to affect the X-ray pattern, at least when the examination is carried out by the Laue method.

These results do not confirm those of Fell, ${ }^{17}$ who has reported that the lines constituting the X-ray pattern differ noticeably in their character according to whether the reflection of the X-ray beam is from unstrained metal or from a strained area. The X-ray diffraction line shown by Fell as typical of the reflection from a strained area is described as "quite continuous, showing that the grain size is extremely small and/or that the crystals are distorted by work," whereas the line from the unstrained metal was "broken up, each dark spot being due to reflection from a small crystal."

It is apparent from other lines of evidence that deformation of the metal, undoubtedly by slip, occurs during loading and gives rise to the strain pattern. The X-ray method, which has proved so useful in other cases in explaining the "mechanism" of slip, is inapplicable

${ }^{17}$ See footnote 8, p. 468. 
B. S. Journal of Research, RP15

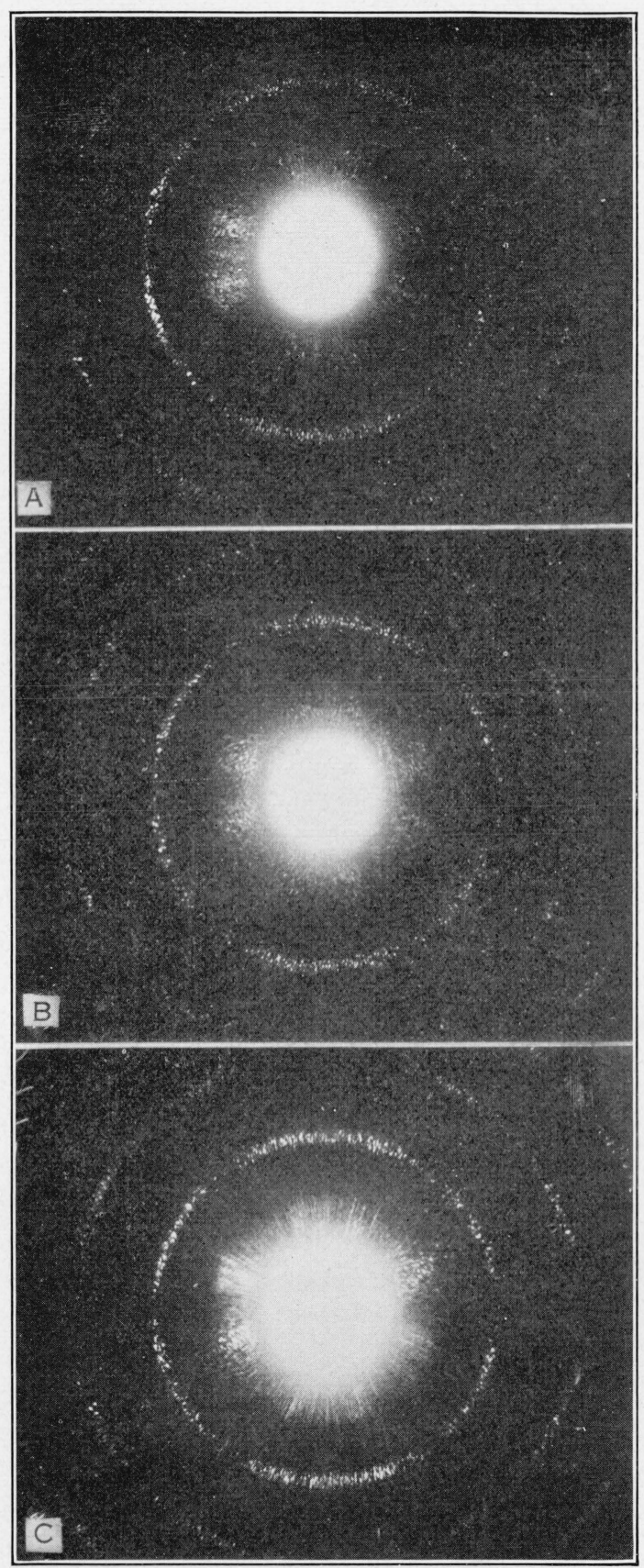

Fig. 8.-X-ray patterns of low-carbon steel. Laue method. A specimen of annealed steel strip 0.0025 inch thick was stressed in tension until strain markings appeared

$a$, "unstrained" metal adjacent to the strain markings; $b$, metal permanently strained, within one of the strain markings; $c$, end of the tension bar where it was gripped. Note the "asterism" caused by the severe deformation 
B. S. Journal of Research, RP15

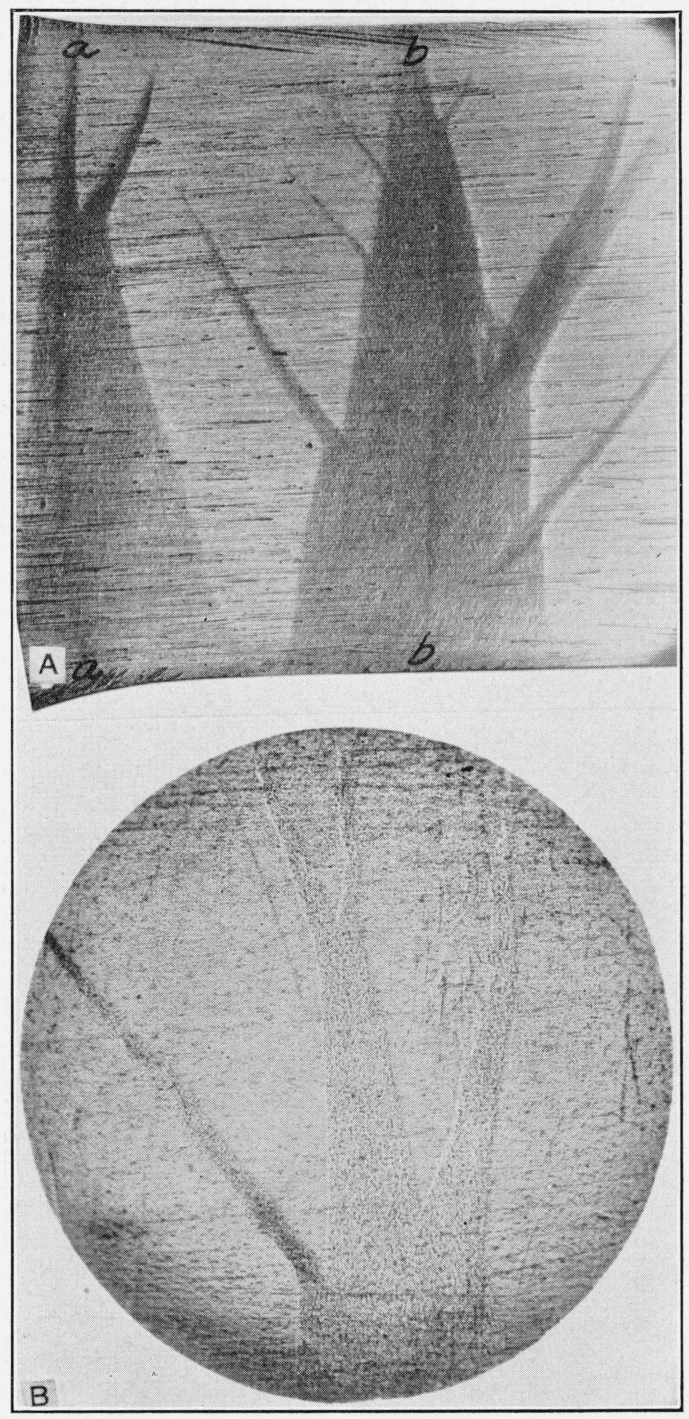

FIG. 9.-Macroscopic appearance of the strain markings on low-carbon steel

$a$, specimen 5 (Table 1). See Figure $11(a) . \times 2$. First line $a$ formed at $28,600 \mathrm{lbs}$./in. ${ }^{2}$, line $b$ at $30,200 \mathrm{lbs}$./in. ${ }^{2}$, load held for ten minutes and the wedges widened, the $45^{\circ}$ branches formed at $32,000 \mathrm{lbs} / / \mathrm{in}^{2}$, no flaking of the scale on the opposite side occurred; $b$, specimen 7 (Table 1 ). See Figure $3(b)$. $\times 31 / 2$. occurred; "r, specimen 7 (Table 1). See Figure 3 (b). $\times 31 / 2$. markings. The direction of stress application was parallel to the shorter dimension of the page 


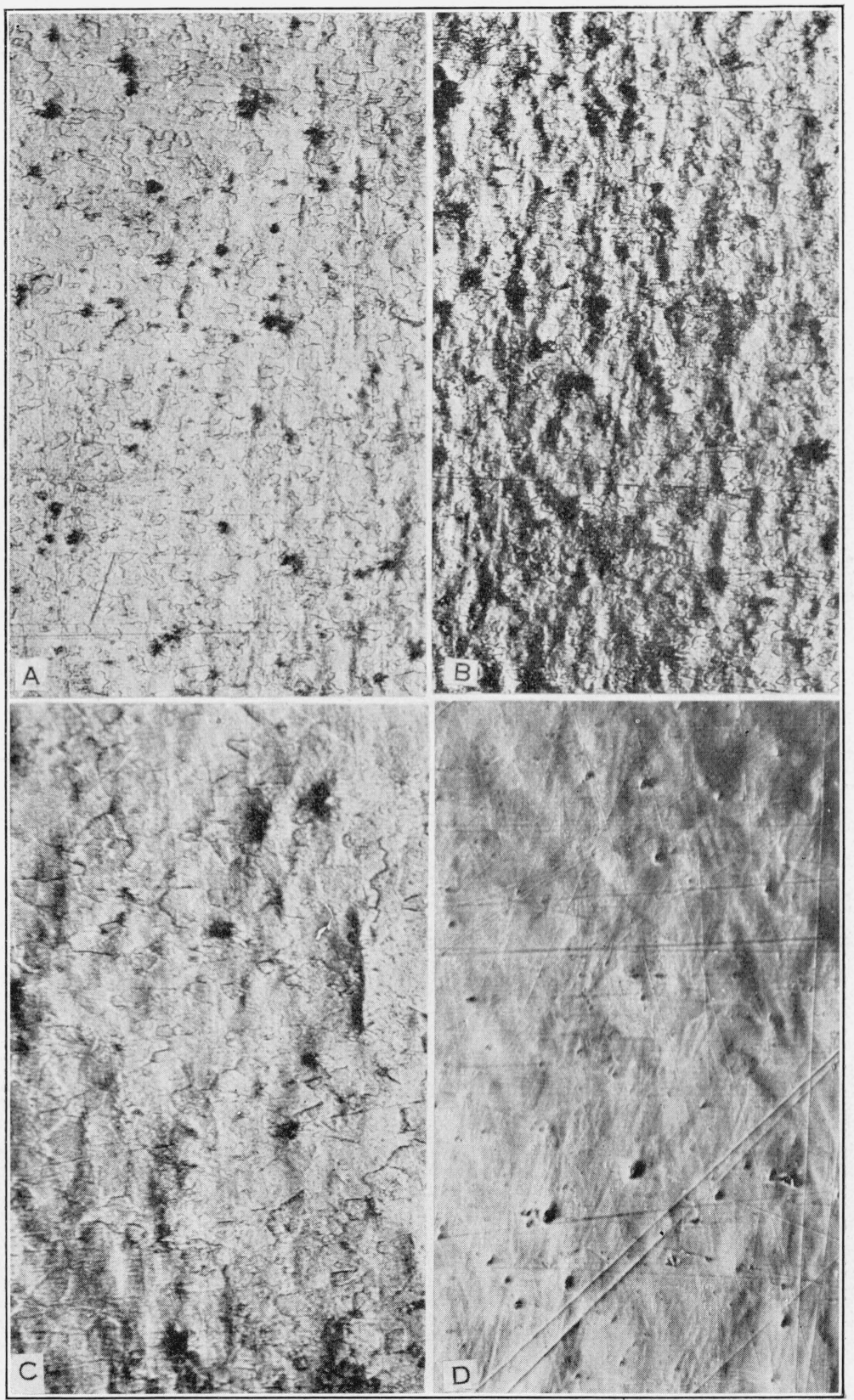

Fig. 10.-Microscopic appearance of the surface of strain markings on lowcarbon steel

Polished strip steel, 0.0025 inch thick, was stressed in tension sufficiently to produce the strain markings, illumination, slightly oblique. $a$, The strained strip was etched to show the grain size. The micrograph shows the boundary of the strained area $\times 100 ; b$, similar to $a$, within a strain marking. $\times 100 ; c$, similar to $b$. $\times 250 ; d$, similar to $b$, unetched. $\times 250$. The direction of stress application was parallel to the shorter dimension of the page. Note the relatively large size of the "ripples" in comparison to the ferrite grain size 


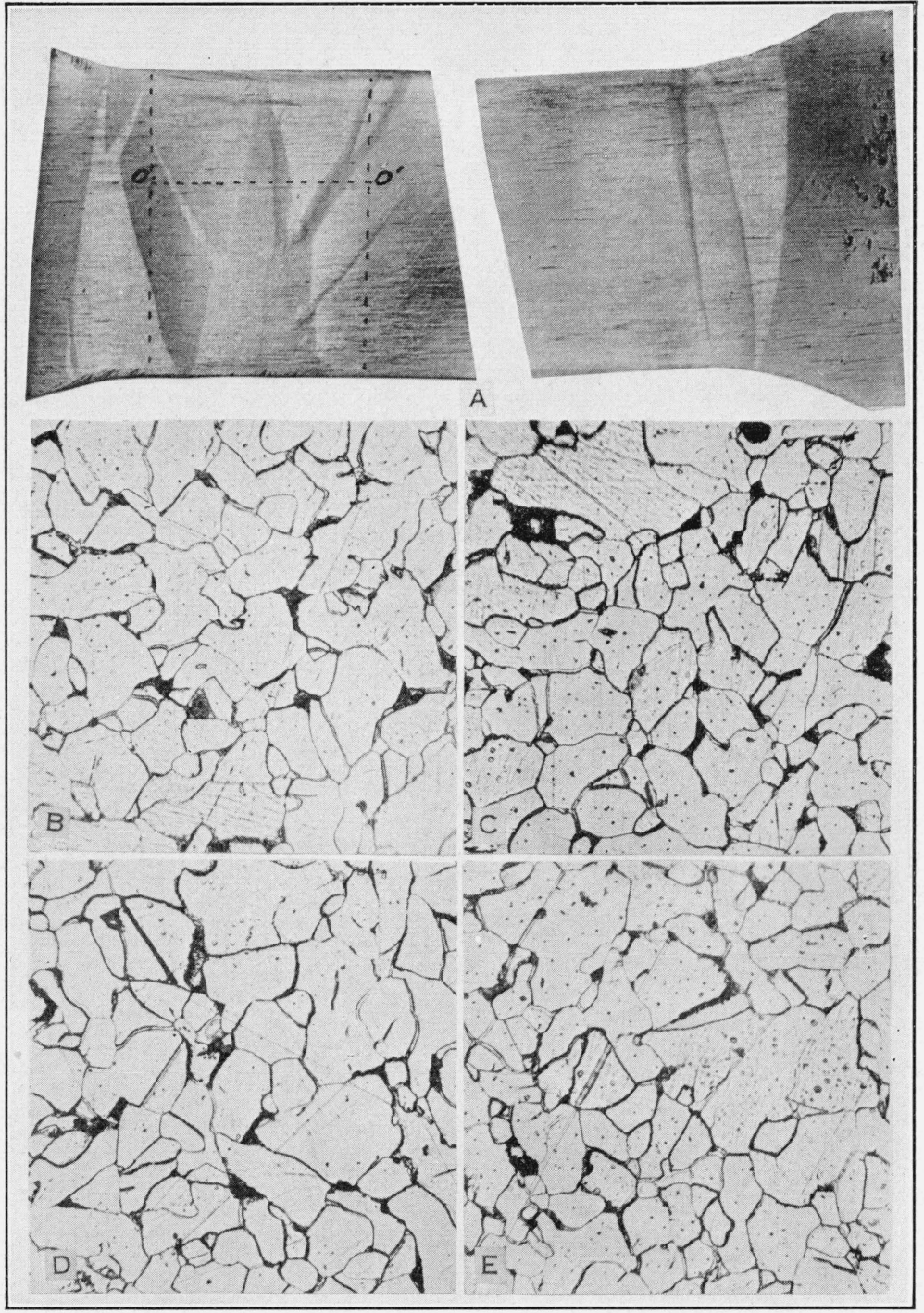

FIG. 11.-Microstructure of low-carbon steel which has been strained suffciently to form strain markings

$a$, ends of specimen 5 (Table 1) showing strain markings. $\times 1$. A section perpendicular to the surface of the bar along $0---0^{\prime}$ was prepared for microscopic examination and micrographs were assembled to show the structure of this entire strip; $b, c$, structure of the metal within the strain marking. $\times 250 ; d, e$, structure of the metal outside of the strain marking. $\times 250$. Etchant, picric acid solution. The structure within the strain marking does not differ essentially from that of the adjacent unstrained metal 
here, however, and any attempt to correlate the strain effect with the crystal structure would be highly speculative.

\section{MICROSTRUCTURE}

When very slightly magnified, the strain marking's are seen to have a "matt finish" in contrast to the polished surface out of which they have been formed. This is illustrated in Figure 9. A higher magnification reveals the fact that the matt appearance of the strain figures is the result of a great number of tiny "ripples," all of which are approximately parallel to one another and arranged perpendicularly to the direction in which the stress was applied. This feature is best seen with slightly oblique illumination and, as shown in Figure $9(b)$, the boundary between the strained and the unstrained portions is a clear and definite one.

The size of these ripples on the surface of the strained areas is very much larger than that of the grains of the metal out of which they are formed. This is shown in Figure 10, which depicts the appearance of the surface of the 0.0025-inch steel strip which after polishing was etched so as to reveal the grain size and then stressed in tension sufficiently to produce the characteristic strain figures. The conclusion would seem to be warranted that in the production of these ripples many of the grains are shifted and tilted bodily possibly in addition to any internal distortion which they may undergo.

The examination of the structure of the interior of a strained bar at points corresponding to the surface strain markings failed to reveal any significant difference between the structure of the strained and the unstrained areas. This is in accord with the results of similar examinations reported by Fell, ${ }^{18}$ who states:

Attempts were made to study the difference in microstructure between the metal constituting the distortion wedge and the adjacent unstrained metal, but no sharply defined change was observed in the material in passing from the strained to the unstrained zones. Evidence of slip could be seen in both zones, although more frequently in the distortion wedges.

Figure 11 is representative of the results obtained in this study. A large number of micrographs were taken of a series of adjacent areas constituting a survey across the strain figure shown (specimen 5, Table 1). These were assembled in proper sequence into a long: strip, over 10 feet long, for more careful study than was possible by visual examination alone with the miscroscope. The micrographs given in Figure 11 are representative. They show no marked features which may be considered as significant of the difference between the strained and the unstrained areas.

${ }^{18}$ See footnote 8, p. 468. 
Specimens from the same tension bar showing prominent strain markings were annealed by heating to $650^{\circ} \mathrm{C}$. and maintaining at this temperature for one hour, after which the microstructure was examined for evidence of recrystallization within the strained portions. As before, a considerable number of micrographs were taken which were assembled in proper sequence to show a "survey" of the structure across a strain marking. In Figure 12 are given micrographs representative of the metal of the strain marking and of the adjacent unstrained metal. As will be seen from the micrographs, both structures were essentially the same; the metal in the strain markings showed no greater evidence of recrystallization, occurring as a result of the annealing treatment which was given the steel, than did the unstrained metal.

A specimen of the 0.0025 -inch strip steel was strained so as to produce conspicuous strain markings. The markings on the two sides of the thin strip were practically identical, and it is evident that the effect of straining as shown by the surface pattern extended entirely through the strip. The position of these markings was then definitely marked by sharp scratches along the boundaries. The surface was then polished for microscopic examination and etched. In Figure 13 are given micrographs representative of the metal within strain figures and of the adjacent unstrained metal. No difference in the microstructure of the metal in the two portions of the sheet, strained and unstrained, is shown by these micrographs.

A portion of the surface of a tension specimen of 0.0025 -inch steel strip was polished, this being done by bending it into a loose coil and embedding a part of it in a matrix of sulphur which was poured around it while molten. It was then etched so as to reveal the grain boundaries and then, after removal from the sulphur matrix, stressed until strain markings showed. The microstructure of the surface corresponding to the strain markings and the adjacent unstrained metal is shown in Figures 14 and 15. The effect of the distortion upon the grain structure is unmistakable. It will be seen that many of the grains show evidence of distortion by slip, the slip bands, as revealed by their traces on the surface, being approximately parallel in the different grains and perpendicular to the direction in which the stress was applied. Not all of the grains show evidence of slip, and in those grains in which it has occurred the general shape and cross-sectional outline of the grain has not been noticeably affected. It is evident from these results that the formation of the strain markings is a slip phenomenon, the slip being confined to those grains which are suitably oriented with respect to the direction of applied stress. 
B. S. Journal of Research, RP15

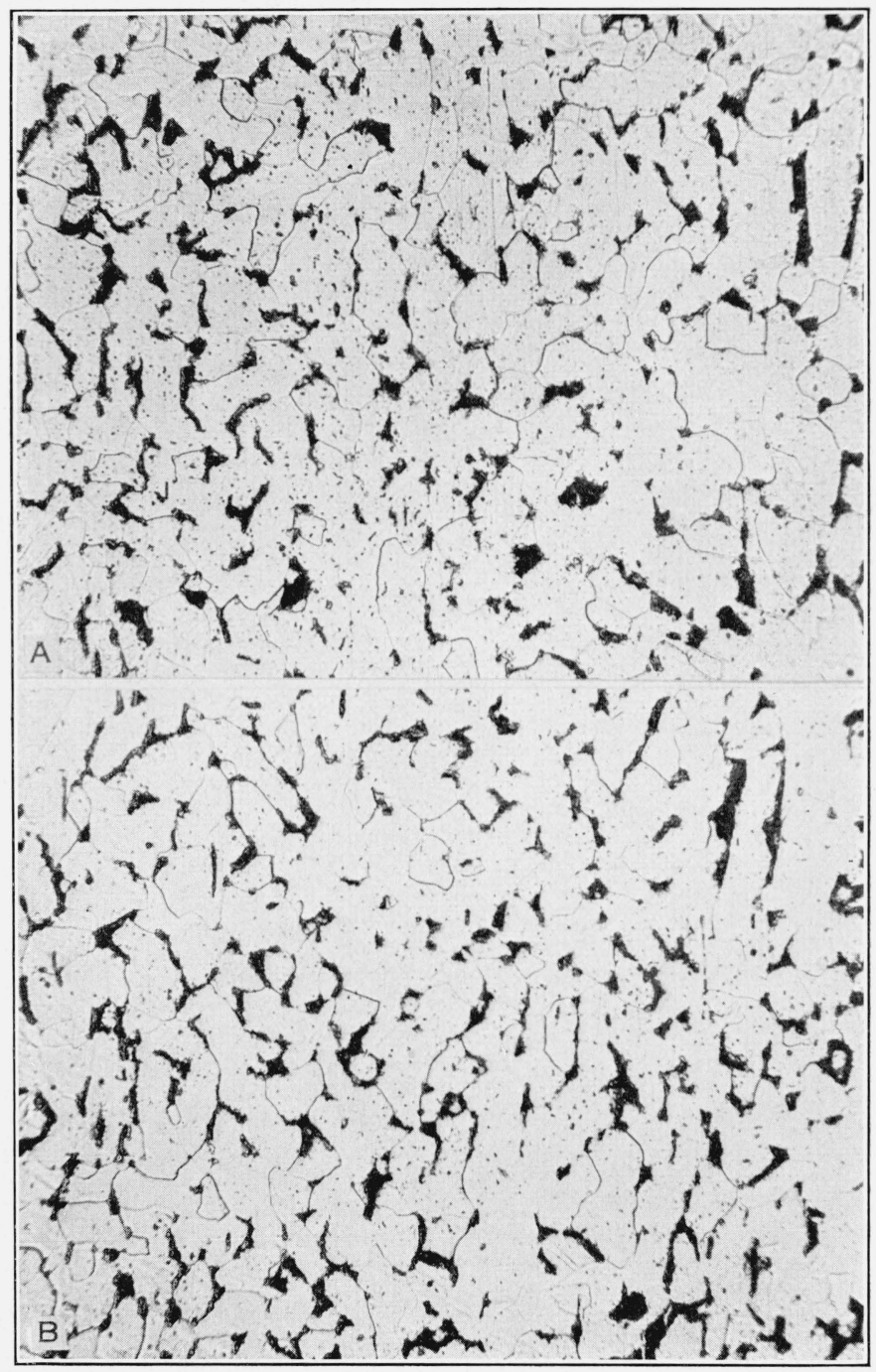

FIG. 12.-Effect of annealing on the microstructure of steel showing strain markings. $\times 250$

The material of Figure 11 was annealed one hour at $650^{\circ} \mathrm{C}$. a, adjacent metal outside strain marking; $b$, metal within the strain marking. The straining which the steel received was not sufficient to cause it to show any greater tendency toward recrystallization than the adjacent unstrained metal 


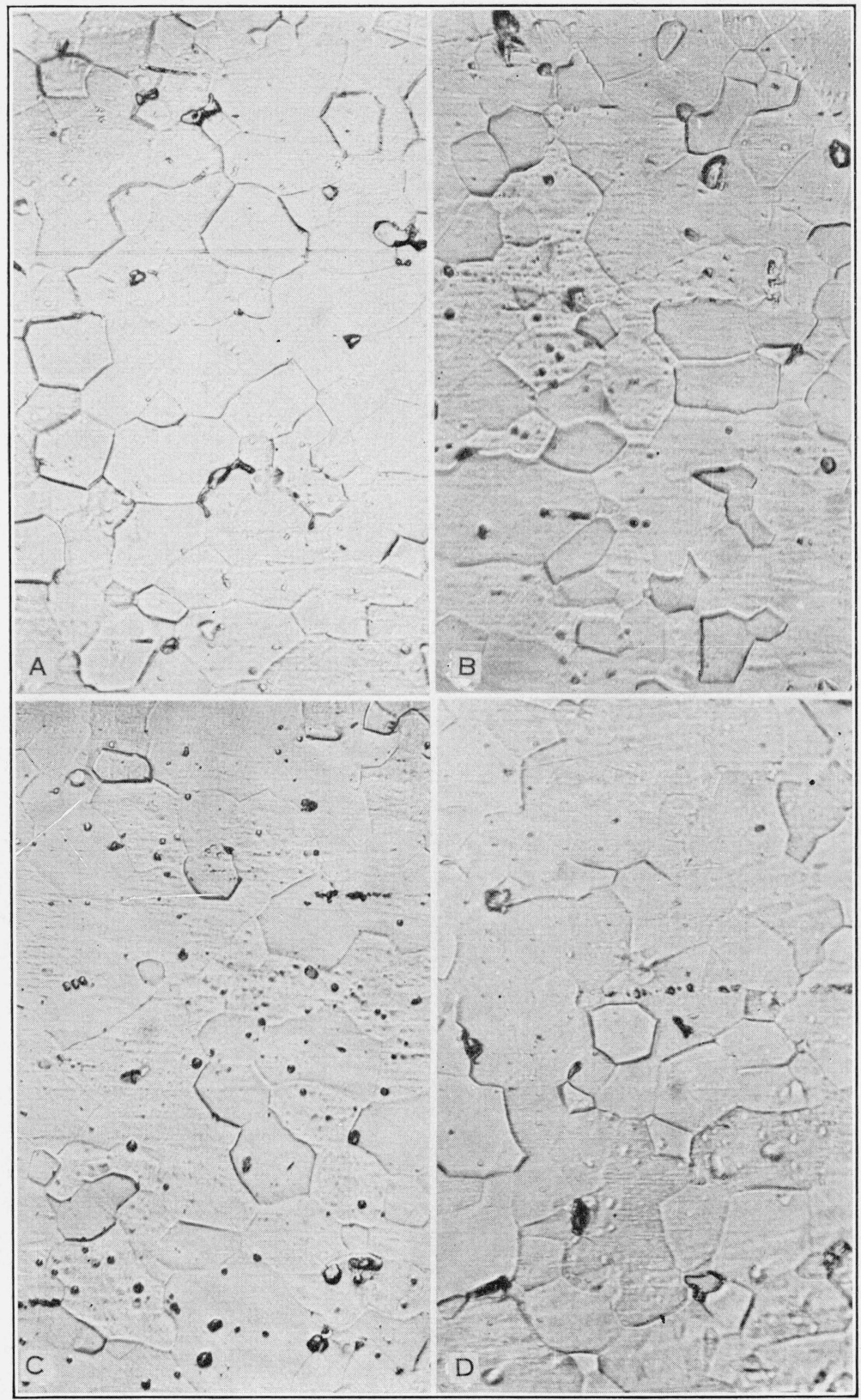

Fig. 13.-Structure of low-carbon steel after straining. $\quad \times 500$

Strip steel (0.0025 inch) after being stressed so as to form strain markings was polished slightly and etched. $a$ and $b$, structure of the metal outside of the strain markings; $c$ and $d$, structure within the strain marking. No evidence of deformation in the structure is shown by this method of examination 


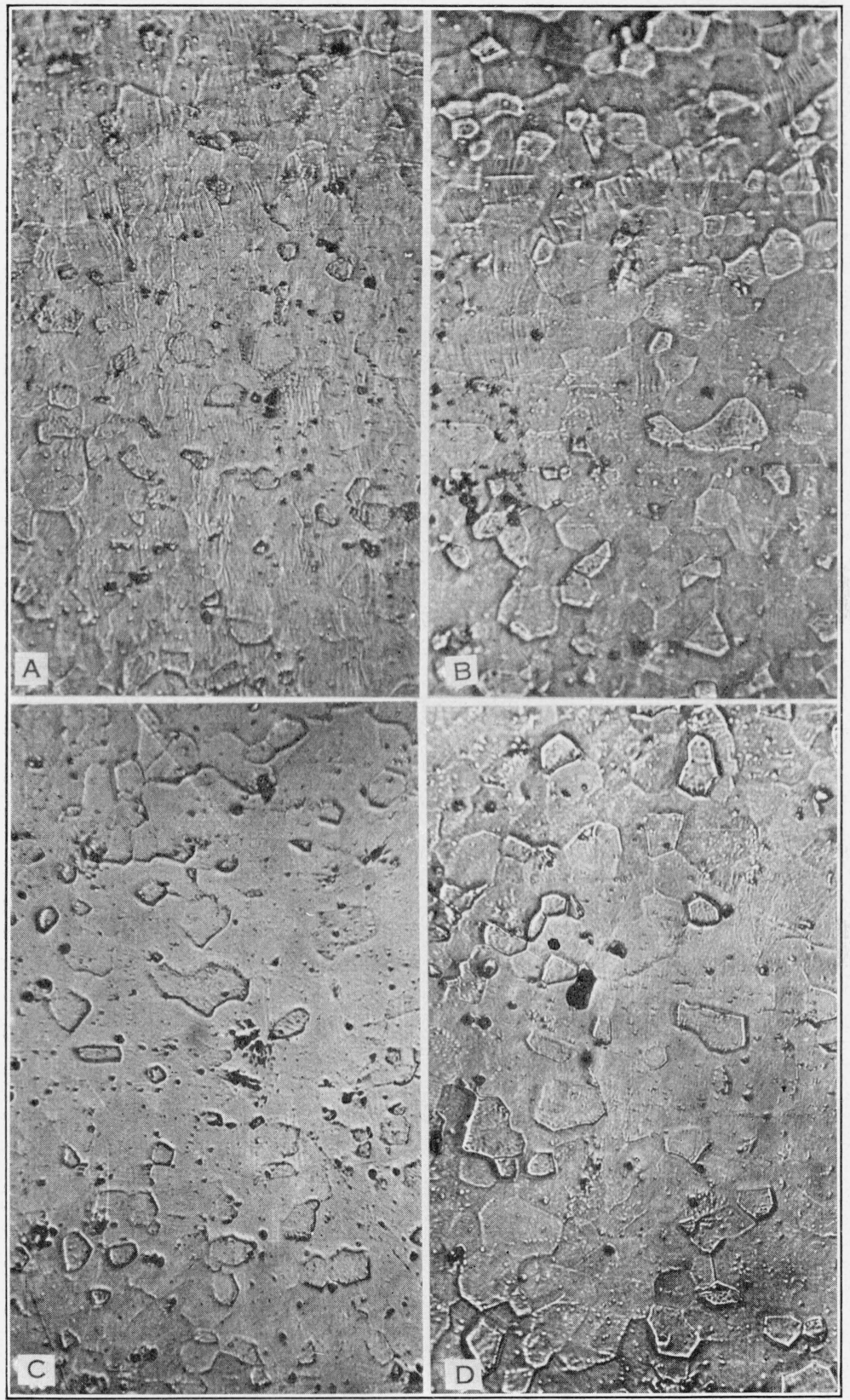

FIG. 14.-Structure of low-carbon steel which has been stressed sufficiently to show strain markings. $\times 250$

Strip steel after being polished and etched was stressed. $a$ and $b$, structure within the strain markings; $c$ and $d$, structure outside of the strain markings. Note the evidence of slip within some of the ferrite grains in the strain markings and the entire absence of it in the grains outside of the strain markings 


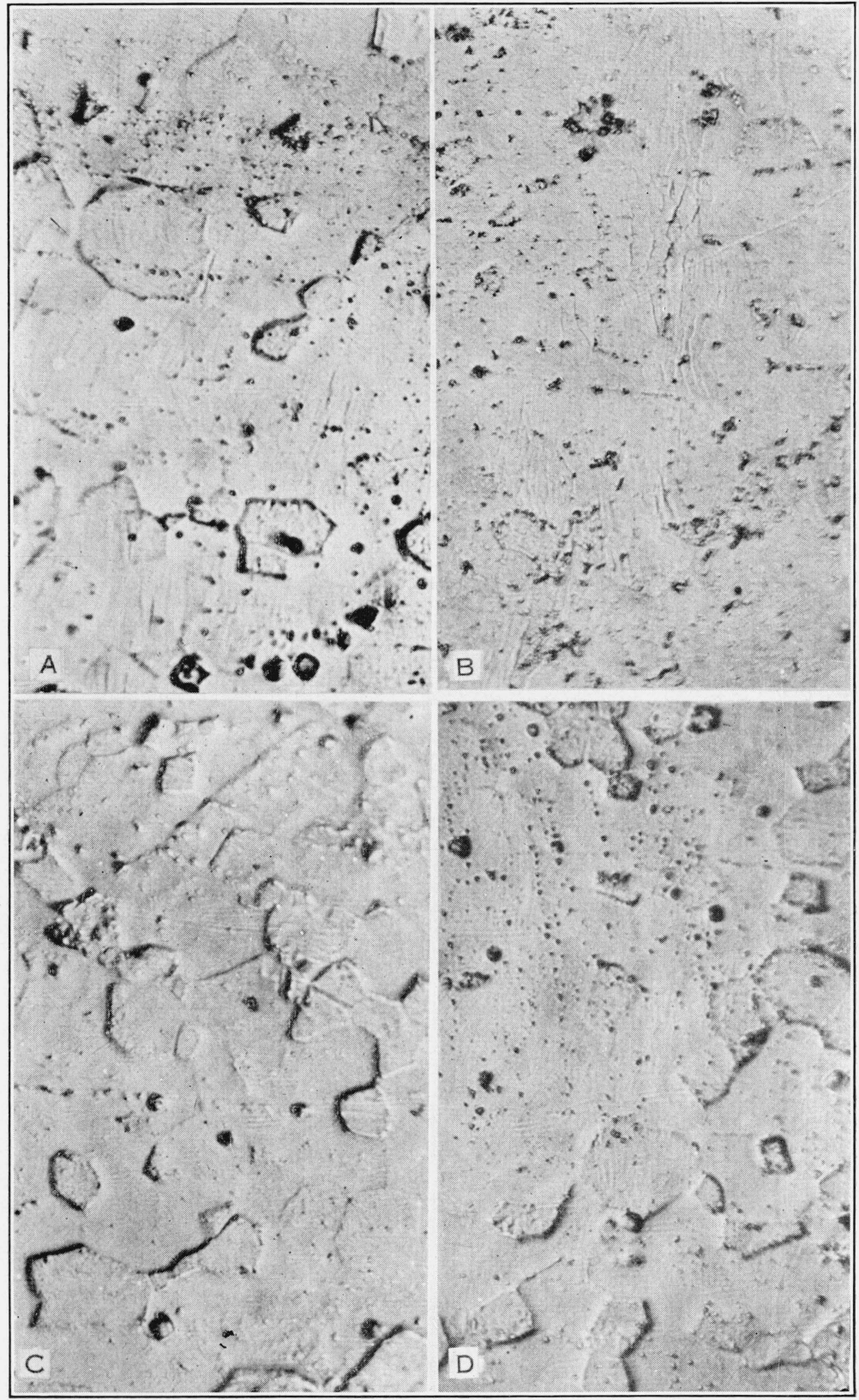

FIG. 15.-Structure of low-carbon steel after being stressed sufficiently to show strain markings. Same material as in Figure 14. $\times 500$

$a$ and $b$, within the strain markings; $c$, outside of the strain markings; $d$, on the edge of the strain marking, left of the diagonal from lower left to upper right corner is outside the strain marking 


\section{COMPARISON WITH AN ALUMINUM ALLOY}

A number of investigators have concluded that strain markings of the kind described in this report are peculiar to iron and soft steel. Jevons ${ }^{19}$ suggests that the behavior of iron in this respect is a consequence of the body-centered cubic space lattice which is characteristic of iron. For purposes of comparison a few tests were made with an aluminum alloy sheet, aluminum being chosen because its crystal structure is different from that of iron and also because strain markings somewhat similar to those on soft steel have been reported ${ }^{20}$ for such material. Tension specimens of the aluminum alloy, $25-\mathrm{S},{ }^{21}$ in sheet form, were stressed in tension. Figure 16 is representative of the results obtained. The stress markings, the formation of which is accompanied by an audible "click," appear as narrow bands extending entirely across the specimen at an angle of slightly less than $60^{\circ}$ with the direction of the applied stress. The continued application of the load results in an increase in the number of such markings, the surface of the specimen becoming covered with a number of parallel bands. Unlike the corresponding strain markings on soft steel, no pronounced "growth" in the band width or in the formation of secondary "branches" was observed with the aluminum alloy under continued application of the load.

\section{DISCUSSION}

Definite proof has been given in the foregoing sections that the markings on polished specimens of mild steel produced by straining, the so-called Piobert, Lüders', or Hartmann lines, are, as has generally been assumed, a special case of the phenomenon of deformation by slip. When a specimen, of the form of the standard tension bar, is subjected to tensile stress, strain markings first appear in the great majority of cases at the ends of the reduced portion of the bar close to the fillet - the most highly stressed portion of the bar according to photoelastic analysis. In the fiat tension bars used in this investigation the first lines to appear were evidently of the nature of "alignment slip"-presumably a consequence of the lack of perfect alignment of the specimen with respect to the direction of the applied loading, even in the best "self-aligning" grips which were obtainable. These first markings usually appeared on the opposite sides of a flat

\footnotetext{
${ }^{10}$ See footnote 7 , p. 468.

${ }^{20}$ R. J. Anderson, "Some mechanical properties of duralumin sheet as affected by heat treatment," Proc. Am. Soc. Test. Matls., 26 (2), p. 349; 1926; also, private communication from R. L. Templin, Aluminum Co. of America.

${ }^{21}$ Described in data sheet Al 5601, Handbook of Am. Soc. Steel Treat.; approximate composition of material used which was kindly supplied for these tests by R. L. Templin, Aluminum Co. of America: $\mathrm{Cu}, 4.2$ per cent; $\mathrm{Fe}, 0.45$ per cent; $\mathrm{Si}, 0.9$ per cent; $\mathrm{Mn}, 0.68$ per cent; $\mathrm{Mg}, 0.10$ per cent. Aged at room temperature after being quenched in water from $520^{\circ} \mathrm{C}$. $\left(970^{\circ} \mathrm{F}\right.$.) approximately.
} 
tensile bar, one at each of the two ends, and progressed across the bar nearly at right angles to the direction of the applied stress, as would be expected if this were an alignment effect. In general, as the load was maintained constant or only slightly increased, the first lines broadened into wedges as they progressed across the bar, although the position of the line of initial slip remained quite evident. Later, branches from the initial wedge appeared, which usually followed a course making an angle of about $50^{\circ}$ with the axis of stress.

In general, as the load is maintained on the bar, the effect progresses toward the center of the bar; that is, away from the shoulder of the specimen by the formation of new markings originating slightly ahead of the advancing "front" in the form of lines which widen into wedges or bands at the edge of the bar. Often, however, "branches" extending relatively far into the unstrained metal in the form of narrow, pointed wedges formed from preexisting markings and constitute a conspicuous feature of the entire pattern. As the "growth" of the pattern progressed by the extension and widening of the lines, "islands" of apparently unstressed metal at very considerable distances back of the advancing "front" not infrequently were observed.

Within the strain markings deformation is not common to all the grains. Under the microscope only part of the grains were found to show evidence of slip, the slip bands in any one grain being nearly parallel to those in the other grains. Evidently only those grains which are so oriented with respect to the axis of stress as to permit slip at relatively low stress values, presumably along the planes of easiest slip, take part in the extension of the bar by slip.

The slight but noticeable roughening of the surface which gives rise to the strain markings is not caused solely by the slip within the favorably oriented grains. As a result of the slip that occurs "ripples" are formed on the surface, the size of which is much greater than the average size of the grains which constitute the metal. Evidently many of the grains in the immediate neighborhood of those in which slip occurs are tilted and shifted bodily to a slight extent, and give rise to the characteristic rippled surface appearance. Takaba and Okuda ${ }^{22}$ have emphasized this aspect in their suggested explanation of the phenomenon. They have also stated that an essential condition for this phenomenon to occur is a sufficient number of grains, and that strain markings are rare in coarsely grained metal. These investigators, however, failed entirely to demonstrate the underlying fundamental cause - that is, deformation by slip within certain favorably oriented grains without which the effect could not be produced.

${ }^{22}$ See footnote 10, p. 468. 
B. S. Journal of Research, RP15

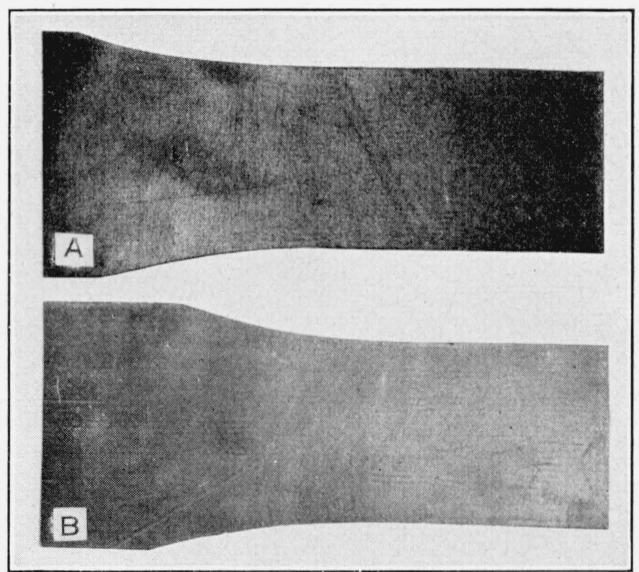

FIG. 16.-Strain markings on an aluminum alloy sheet. $\times 1$

The alloy, $25 \mathrm{~S}$ (see note 21 ) was used 
It is very fascinating to watch a tension specimen while it is maintained under a load just sufficient to cause the formation of strain markings. The pronounced localization of the deformation; the very definite boundaries separating the permanently strained portions from the metal which, as yet, shows no evidence whatever of permanent strain; the slow, often intermittent, advance of the boundary as the condition of permanent strain advances into the "unstrained" metal, all serve to emphasize the fact that the process of the permanent straining or "yielding" of a metal bar in tension is progressive in nature. The permanent deformation of the entire bar is not accomplished instantaneously even after the first yielding has taken place. Observations on the behavior of a bar subjected to a series of successive loadings, each of which is just sufficient to cause yielding, serves to demonstrate this phenomenon very strikingly. When the bar was restressed, after having been removed from the machine in order that the effect of the previous load might be studied, it was seen that the straining process was resumed where it had "left off" when the previous load was released - that is, the strain markings which appear with the new loading form as an extension and continuation of those already present. Not until the straining effect has covered the entire reduced section of the specimen does there appear to be any further deformation in those portions which have already yielded under load. As was shown by the hardness determinations, these strained portions are hardened considerably by the cold-working they receive in the initial straining. Although the degree of strengthening of the steel is much less than that produced when the specimen is strained sufficiently to cause fracture, the steel is definitely stronger than the unstrained metal; hence, no further yielding would be expected in the initially strained portions until the stress on the bar had been increased somewhat.

As the load is gradually increased, after the initial straining of the entire reduced section has been accomplished, further extension takes place which is apparently quite uniformly distributed over the entire reduced section of the bar. This continues until the "neckingdown" of the bar or localization of the deformation preparatory to fracture occurs. The pronounced flow which normally takes place in mild steel when loaded to the point of fracture wipes out almost completely all evidence of the previously formed strain markings. Only traces of the most conspicuous ones remain on the matt surface of the pulled bar, as is shown in Figure $5(b)$. In the tension test as ordinarily carried out the rather rapid rate at which the load is applied, together with the fact that the surface of the specimen is not polished, render the effects described above, which constitute the yielding of the bar, inconspicuous so that they are often overlooked entirely. 
It has been well established by the early work of Bauschinger, ${ }^{23}$ Muir, ${ }^{24}$ and others that the elastic properties of iron are very materially affected by overstraining the metal. It follows, however, from the results obtained by the progressive loading of a bar in tension, summarized in Figure 2, that the degree of overstrain to which a specimen - for example, a tension bar-is subjected must be sufficient so that the entire reduced section is permanently strained. Otherwise the elastic properties which will be measured when the load is applied a second time to the bar will be those of the initial material; that is, of those portions of the bar which were not permanently strained during the first loading. This follows directly from the fact that the permanent deformation of a bar under tension is decidedly localized. As already explained, only a small part of the bar is initially affected, and this effect progresses gradually along the length of the bar as the load is maintained. In the experiment summarized in Figures 2 and 6 during each of the four successive loadings after the first only a rather small additional part of the reduced section of the bar was permanently strained, the total effect of the five loadings constituting the straining of approximately the entire reduced section. The elastic properties measured during each of these five loadings, therefore, were those of that part of the reduced section of the bar which had escaped permanent straining in the previous loadings. Changes of the character of those reported by Bauschinger and Muir undoubtedly would occur within the strained portions. In a tension test, however, these changes are not apparent unless the entire reduced section of the bar has been subjected to overstrain.

Handford ${ }^{25}$ has described a method for the measurement of slip in metals by means of which measurements of slip of the order of 65 Angstrom units $\left(1 \AA\right.$ Angstrom unit $=10^{-8} \mathrm{~cm}$ ) were reported. The method, which involves the use of thermionic tubes, depends upon the alteration of capacity of a condenser of which the specimen forms a part. The results reported for a normalized steel of approximately the same carbon content $(0.25$ per cent) as the material used in this investigation are of interest. The valve indicator showed slip at a stress of $31,800 \mathrm{lbs}$./in. ${ }^{2}$, which is in very good agreement with the results obtained here.

A comparison of the tensile properties of single crystals of iron with the stress values at which the first evidence of permanent strain was observed is of interest. Edwards and Pfeil ${ }^{26}$ have deter-

${ }^{23}$ J. Bauschinger, Über die Veränderung der Elasticitätsgrenze und Festigkeit des Eisens durch Strecken, Mitteilungen aus dem Mechanisch-Technischen Laboratorium der K. Polytechnische Schule in München 13, 1886.

${ }^{24}$ J. Muir, “On the recovery of iron from overstrain,” Phil. Trans. Royal Soc. London, A 193, p. 1; 1900.

${ }^{25}$ C. Handford, “A valve method for detecting minute slip in metals," Phil. Mag. 47, p. 896; 1924.

${ }^{20} \mathrm{C}$. A. Edwards and L. B. Pfeil, "The tensile properties of single crystals and the influence of crystal size upon the tensile properties of iron,” J. Iron and Steel Inst., 112, p. 79; 1925. 
mined the tensile properties of iron crystals and reported values for the proportional limit varying from 4,250 to $5,500 \mathrm{lbs}$./in. ${ }^{2}$, values for the tensile strength varying from 21,000 to $34,400 \mathrm{lbs} . / \mathrm{in} .^{2}$, and elongation 31 to 84.5 per cent. It is apparent that the behavior observed for any tensile specimen with respect to the stress at which deformation occurs is characteristic of the aggregate and bears no very obvious relationship to the individual grains which constitute the specimen.

The X-ray method of examination has given a great deal of information as to the mode of deformation occurring during the coldworking of metals in general. In the straining of metals just sufficiently to produce strain markings the total deformation is extremely slight as compared with that which occurs during ordinary cold-working, either by drawing or rolling. X-ray examinations, both by reflection and by the Laue method, have shown no marked difference between the unstrained metal and the same which has received the initial permanent strain resulting in surface strain markings. Microscopic examination has definitely shown evidence of slip in at least some of the grains. Any discussion, however, as to the probable crystallographic planes along which the slip occurs and the relationship of such planes to the direction of stress application would be highly speculative. The simplest assumption is that slip is confined to those grains in which the planes of "easy slip" are definitely oriented with respect to the $45^{\circ}$ planes of maximum shear, there being, probably, an approximate parallelism between the two.

The term "yield point," as applied to metals, is usually defined as follows: ${ }^{27}$ "The stress in a material at which there occurs a marked increase in strain without an increase in stress." It has generally been assumed that the appearance of strain markings of the kind described here indicates that the yield point of the material has been reached or slightly exceeded. That this assumption is sound is shown by the results obtained in this study. However, a definition of yield point based arbitrarily upon a given deformation for a given lengthfor example, 0.01-inch deformation over a length of 2 inches-may be open to criticism. If the results summarized in Figures 2 and 6 are examined on the basis of this arbitrary definition, the conclusion would seem to be justified that the specimen reached its "yield point" only after the fifth loading, although unmistakable evidence of strain markings existed after each of the four previous loadings. In fact, the determination of the stress at which the first evidence of distinct yielding is shown on a polished surface would seem to be a very good. method for the determination of the proportional limit.

In carrying out this study of strain markings on steel only slight attention was given to the subject of revealing this effect by etching:

${ }_{27}$ "Tentative methods of tension testing of metallic materials, E 8-24 T," Proc. Am. Soc. Test. Matls., 24, p. 1081; 1924. 
reagents such as that described by Fry. ${ }^{28}$ It was considered that the excellent results reported by Jevons ${ }^{29}$ has fully demonstrated the correlation between strain effects and etch figures; further confirmation appeared to be unnecessary.

\section{SUMMARY}

1. A study of the strain markings, the so-called Lüders, Piobert, or Hartmann lines, on low-carbon steels has been made. Observations on polished specimens stressed in tension, together with strain measurements on the same, show that the first appearance of the strain markings on the polished surface coincided with the yielding of the metal and, in fact, indicated the proportional limit of the metal very closely.

2. The strain markings practically always appear first on a tension specimen at the ends of the reduced section, close to the fillet. The first lines to appear, in the work reported here, lacked the $45^{\circ}$ orientation usually considered typical of these markings but formed approximately at right angles to the length of the bar. As the load is maintained or increased slightly above that at which yielding occurs, the strain markings gradually progress along the reduced section from the two ends. Extension of the strain pattern toward and into the shoulder ends of the specimen occurs only late in the tension test. The "propagation" of the strain along the bar shows itself by both the widening and branching of the lines and the formation of new ones usually just ahead of the advancing front. The examination of a specimen after being loaded several times in succession, with intermediate release of the load, shows that at each new loading the strain markings form as continuations and extensions of those already formed at the time of the release of the previous loading and continue in a similar manner with each new loading until the entire reduced section of the bar has been affected. No increase in the elastic properties by "overstrain" can occur until this has been accomplished. With further increase of the load, the strain markings are obscured as a result of the pronounced flow of the metal which, up to the time when "necking down" occurs, is distributed quite uniformly over the entire length of the reduced section. The location of the fracture in bars stressed to failure in the great majority of cases appears to bear no obvious relationship to the preexisting strain markings.

3. On surfaces covered with oxide (mill scale) strained areas can be located by the flaking of the scale. The method is a qualitative one, however, and can not be used for precise determination of the stress at which yielding occurs or for showing the fine details of the strain markings. 
4. The hardness of the steel used in these tests was increased approximately 5 per cent locally by the straining which results in the formation of the strain markings. However, this increase in hardness is only about 10 per cent of the increase in hardness produced by straining the same material to the point of fracture.

5. X-ray examination failed to reveal any significant difference between the metal within the strain markings and the immediately adjacent metal which was not permanently strained.

6. Examination of the structure of the interior of the bar showed no significant difference in structure in the strained and the unstrained portions. After annealing at $650^{\circ} \mathrm{C}$. for one hour no marked tendency toward recrystallization or grain growth was shown by the permanently strained metal. On the polished and etched surface of specimens subsequently strained sufficiently to produce strain markings evidence of slip was shown by some of the grains within the strain markings. The slip bands within any grain are approximately parallel to those within the other grains showing slip, and the traces of the slip planes as seen on the surface are nearly at right angles to the direction of the applied stress. Evidently slip occurs only within those ferrite grains which are favorably oriented with respect to the applied stress.

7. Under low magnifications the metal surface within the strain markings has a "rippled" appearance. Each individual ripple is very much larger than the ferrite grains constituting the metal. Evidently, as a result of the deformation by slip which occurs within some of the grains, other grains are tilted and shifted bodily, thus giving the previously polished surface a "matt finish" within the strain markings.

8. Observations on polished specimens serve admirably to demonstrate the progressive character of the yielding of a metal under tensile stress. A specimen may show in its strain marking very considerable evidence of having yielded and still be below its "yield point," according to some of the definitions of this term which depend upon an arbitrarily determined amount of extension over a given length.

9. Strain markings, similar in many respects to those which form on soft steel, were formed on an aluminum alloy sheet used for comparison.

The author is deeply indebted to J. R. Freeman, jr., metallurgist, for his interest in this work in conducting the tension tests and extensometer measurements, and to Samuel Epstein, associate metallurgist, for much of the photographic work. C. E. Eggenschwiler, junior scientific aid, has also contributed greatly in the attainment of the results, especially by his very careful work in the numerous microstructural studies necessary.

Washington, June 9, 1927. 

The July, 1928, number (Vol. 1, No. 1) of the JouRNaL contains the following research papers:

RP1. Accelerated Tests of Organic Protective Coatings. Percy H. Walker and E. F. Hickson.

RP2. Measurement of the Tread Movement of Pneumatic Tires and a Discussion of the Probable Relation to Tread Wear. W. L. Holt and C.M. Cook.

RP3. Absolute Methods in Refiectometry. H. J. McNicholas.

RP4. Interferometer Measurements of Wave Lengths in the Vacuum Arc Spectra of Titanium and Other Elements. C. C. Kiess.

RP5. Analysis of Bauxite and of Refractories of High Alumina Content. G. E. F. Lundell and J. I. Hoffman.

The August, 1928, number (Vol. 1, No.2) of the JouRnal contains the following research papers:

RP6. Some Measurements of the Transmission of Ultra-Violet Radiation Through Various Kinds of Fabrics. W. W. Coblentz, R. Stair, and C. W. Schoffstall.

RP7. Tinting Strength of Pigments. H. D. Bruce.

RP8. Wave-Length Measurements in the Arc and Spark Spectra of Hafnium. William F. Meggers.

RP9. Tests of the Effect of Brackets in Reinforced Concrete Rigid Frames. Frank E. Richart.

RP10. Accelerated Laboratory Corrosion Test Methods for Zinc-Coated Steel. Edward C. Groesbeck and William A. Tucker.

These will be available as separates for purchase from the Superintendent of Documents, United States Government Printing Office, Washington, D. C.

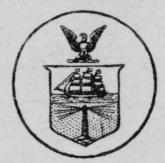

